\title{
Protective effects of Erythronium japonicum and Corylopsis coreana Uyeki extracts against 1,3-dichloro-2-propanol-induced hepatotoxicity in rats
}

\author{
Seunghyun Kim ${ }^{1}$, Hee-Ock Boo ${ }^{2}$, Taeho Ahn ${ }^{1 *}$ and Chun-Sik Bae ${ }^{1 *}$ (B)
}

\begin{abstract}
Erythronium japonicum (E. japonicum) and Corylopsis coreana Uyeki (C. coreana Uyeki, Korean winter hazel) have been shown to significantly decrease 1,3-dichloro-2-propanol (1,3-DCP)-induced generation of reactive oxygen species and CYP2E1 activity in HuH7, human hepatocytes. In this study, we expanded upon the previous study and investigated the effects of E. japonicum and C. coreana Uyeki extracts on 1,3-DCP-induced liver damage in rats. The pre-treatment of rats with these extracts alleviated a decrease in body weight and reduced 1,3-DCP-induced increase in catalytic activities of hepatic enzymes, such as aspartate aminotransferase and alanine aminotransferase, in the serum. Moreover, treatment with the extracts restored the 1,3-DCP-induced decreases in anti-oxidant enzyme activities, such as the activities of superoxide dismutase and catalase, in the rat liver. Histopathological studies also strongly supported the results of enzyme activities. These results suggest a possibility that the extracts of $E$. japonicum and C. coreana Uyeki can be a remedy for alleviating 1,3-DCP-induced liver damage in animals.
\end{abstract}

Keywords: Erythronium japonicum, Corylopsis coreana Uyeki, 1,3-dichloro-2-propanol, Liver, Rats

\section{Introduction}

1,3-Dichloro-2-propanol (1,3-DCP) is a highproduction-volume chemical that was shown to have toxicological properties by the National Institute of Environmental Health Sciences. There is concern regarding the exposure of humans in the workplace during the manufacturing and use of chemicals such as epichlorohydrin, 1,2,3-trichloropropane, and 1,3-dichloropropene (Hammond and Fry 1999). In particular, exposure to 1, 3-DCP may occur through the diet via the addition of hydrochloric acid-hydrolyzed vegetable protein, and through drinking water with added epichlorohydrin polyamine polyelectrolytes used as flocculants and coagulants in water purification (Nyman et al. 2003). In a

\footnotetext{
* Correspondence: thahn@jnu.ac.kr; csbae210@jnu.ac.kr

${ }^{1}$ College of Veterinary Medicine, Chonnam National University, Gwangju 61186, South Korea

Full list of author information is available at the end of the article
}

previous study in rats, the intraperitoneal (i.p.) injection of 1,3-DCP induced drowsiness, liver injury, significant increase in the activity of serum alanine aminotransferase (ALT), decreased white blood cell and platelet counts, and increased blood clotting time (Katoh et al. 1998).

Erythronium japonicum is a perennial herb belonging to the fawn lily family, and is found throughout Japan, Korea, northeast China, Sakhalin, and the Kurile Islands. Regarding its pharmacological properties, Heo et al. (2007) reported that E. japonicum extract has 2,2-diphenyl-1-picrylhydrazyl free radical scavenging activity and exerts anti-proliferative effects in human colorectal carcinoma cells. Corylopsis coreana Uyeki (C. coreana Uyeki, Korean winter hazel), belonging to the Hamamelidaceae family, is cultivated as an ornamental plant and is native to South Korea. Some species of the genus Corylopsis, such as Hamamelis virginiana (witch hazel), have been used as traditional herbal medicines for the 
treatment of irritated skin and inflammatory disease (Kim et al. 2013). In addition, the plant exhibits antiirritant, anti-inflammatory, and anti-tumor effects (Korting et al. 1993; Deters et al. 2001; Lizárraga et al. 2008).

In a recent study using the extracts of $E$. japonicum and C. coreana Uyeki, 1,3-DCP-induced generation of reactive oxygen species and CYP2E1 activity was shown to significantly decrease in $\mathrm{HuH7}$, human hepatocytes (Bae et al. 2018). Boo et al. (2013) also suggested that the extracts exhibited strong inhibitory activities against $\alpha$-amylase and $\alpha$-glucosidase and scavenged 1,1-diphenyl-2-picrylhydrazyl radicals in vitro.

In the present study, we evaluated the effects of $E$. japonicum and C. coreana Uyeki extracts against liver damage induced by 1,3-DCP treatment in rats.

\section{Materials and methods}

\section{Animals and environmental conditions}

Seven-week-old male Sprague-Dawley rats, weighing $269.5 \pm 16.54 \mathrm{~g}$, were provided by Samtako Bio Korea Co., Ltd. (Osan, South Korea) and were used after 1 week of quarantine and acclimatization. They were housed in an air-conditioned room with a $12 \mathrm{~h}$ light/ dark cycle under controlled illumination (200-300 lx), temperature $\left(23 \pm 2{ }^{\circ} \mathrm{C}\right)$, and humidity $(55 \pm 10 \%)$. Tap water and commercial rodent diet (Samyang Feed, Wonju, South Korea) were provided ad libitum. The Institutional Animal Care and Use Committee of Chonnam National University approved the protocols for the animal study, and the animals were cared for in accordance with the Guidelines for Animal Experiments of Chonnam National University.

\section{Test chemicals and treatment}

E. japonicum and C. coreana Uyeki plant extracts were provided by WellPhyto Co. (Gwangju, South Korea). 1,3DCP was purchased from Sigma Aldrich (Merck Millipore, Darmstadt, Germany). The extracts (2 or 5\%) were administered orally in $10 \mathrm{~mL} / \mathrm{kg}$ doses, calculated based on the average daily intake of the animals, at a regular time once per day for 7 days. To induce liver injury following the final dose of the extract, rats were administered 1,3-DCP aqueous solution $(1 \mathrm{~mL} / \mathrm{kg})$ at doses of $80 \mathrm{mg} / \mathrm{kg}$ as a single i.p. injection.

\section{Experimental groups}

The animals were randomly divided into six experimental groups ( $n=7$ per group) as follows: 1$)$ negative control group; 2) 1,3-DCP-treated group that received a single dose of 1,3-DCP, which has been shown to induce acute hepatotoxicity in rats (Katoh et al. 1998); 3) $2 \% E$. japonicum extract group; 4) $5 \% \mathrm{E}$. japonicum extract group; 5) $2 \%$ C. coreana Uyeki extract group; and 6) 5\% C. coreana Uyeki extract group. Groups 3-6 were treated with the plant extract orally once daily during the experimental period.

\section{Clinical observation and body weight}

All animals were observed once daily for mortality and clinical signs of reaction to the treatment. The body weight and weight gain of each animal were measured at the end of treatment and before the animal was sacrificed.

\section{Serum biochemical analysis}

The animals were anesthetized with a combination of xylazine hydrochloride (Rompun; Bayer Korea, Korea; $10 \mathrm{mg} / \mathrm{kg}$ ) and ketamine (ketamine $\mathrm{HCl}$; Yuhan Co., South Korea; $40 \mathrm{mg} / \mathrm{kg}$ ) after the 1,3-DCP injection. Blood samples were collected by venipuncture from the posterior vena cava. Each sample was centrifuged at $3000 \mathrm{rpm}$ for $15 \mathrm{~min}$ within $30 \mathrm{~min}$ after collection, after which the top serum layer was removed. Aspartate aminotransferase (AST) and alanine aminotransferase (ALT) in the serum were measured using an auto-analyzer (Dri-chem 4000i; Fujifilm Co., Tokyo, Japan).

\section{Superoxide dismutase (SOD) and catalase (CAT) assays}

After the collection of blood samples, all animals were sacrificed by blood-letting. The liver was harvested and the absolute and relative (organ-to-body) weights were measured. Samples from the liver tissue were washed in phosphate buffered saline and stored at $-80^{\circ} \mathrm{C}$ for the measurement of SOD and CAT. The frozen liver samples were homogenized in a glass-Teflon homogenizer with $50 \mathrm{mM}$ phosphate buffer ( $\mathrm{pH}$ 7.4) to obtain 1:9 (w/ v) whole homogenate. The homogenates were centrifuged at $11,000 \times g$ for $15 \mathrm{~min}$ at $4{ }^{\circ} \mathrm{C}$ to remove any cell debris. SOD activity was determined according to the method of Beauchamp and Fridovich (1971). The final supernatant, containing $50 \mathrm{mM}$ carbonic buffer $(\mathrm{pH}$ 10.2), $0.1 \mathrm{mM} \mathrm{Na}_{2}$-EDTA, $0.1 \mathrm{mM}$ xanthine, and 0.025 $\mathrm{mM}$ nitroblue tetrazolium (NBT), was illuminated at $25^{\circ} \mathrm{C}$ for $10 \mathrm{~min}$. Then, xanthine oxidase $\left(3.3 \times 10^{-6}\right.$ $\mathrm{mM}$ ) was added to the reaction mixture, and the reduction of NBT was measured spectrophotometrically at $560 \mathrm{~nm}$. CAT activity was determined using the method of Aebi (1984). A decrease in the absorbance of $\mathrm{H}_{2} \mathrm{O}_{2}$ was measured spectrophotometrically at $240 \mathrm{~nm}$ in $1 \mathrm{~mL}$ of reaction mixture containing $10 \mathrm{mM} \mathrm{H}_{2} \mathrm{O}_{2}$ and $20 \mu \mathrm{L}$ supernatant in $50 \mathrm{mM}$ potassium phosphate buffer $(\mathrm{pH}$ 7.0). CAT activity was expressed as 1 mole of $\mathrm{H}_{2} \mathrm{O}_{2}$ decomposed $\mathrm{mg}$ protein ${ }^{-1} \mathrm{~min}^{-1}$ at $\mathrm{pH} 7.0$ at $25^{\circ} \mathrm{C}$. Total protein concentrations were determined using Bradford assay with bovine serum albumin as the protein standard. 


\section{Histological analysis}

Dissected liver tissues were fixed in 10\% neutral buffered formalin and embedded in paraffin. The paraffinembedded sections were cut into 4- $\mu \mathrm{m}$ thickness, deparaffinized, and rehydrated using standard techniques. The liver sections were stained with hematoxylin and eosin. Histological changes, such as hepatocyte degeneration/ necrosis and inflammatory cell infiltration of the liver, were observed using a microscope.

\section{Statistical analysis}

The data were analyzed by using GraphPad InStat version 3.0 (GraphPad Software, Inc., La Jolla, CA, USA). The results were expressed as the mean \pm standard deviation. Differences between groups were analyzed by oneway analysis of variance followed by Dunnett's multiple comparison test. A $P$ value of $<0.05$ was considered to indicate a statistically significant difference.

\section{Results and discussion}

As a preliminary test prior to the evaluation of the antioxidative effects of the E. japonicum and C. coreana Uyeki extracts, we first examined the clinical signs in rats induced by the extracts, such as effects on mortality, body weight, and the liver. In toxicological studies, body and organ weights generally indicate the presence of potentially toxic chemicals (Kim et al. 2004; Lee et al. 2009). Treatment-related mortality and clinical signs were not observed in all rats tested during the study period (results not shown). In contrast to the gain in body weight observed in rats in the control group, the rats treated with 1,3-DCP alone showed the most significant decrease in body weight (Table 1). However, 2\% and $5 \%$ E. japonicum (or C. coreana Uyeki) treatment after 1,3-DCP administration resulted in a slight decrease in the weight, which was not statistically significant. Therefore, these results suggested that $E$. japonicum or C. coreana Uyeki extracts may exert protective effects against the decrease in body weight induced by 1,3-DCP. However, a dose-dependent protective effect was not observed, as the extent of weight loss was similar at both treatment concentrations. In contrast to the change in body weight, no significant differences was observed in the relative weights of the rat liver (weight ratio of body to tissue) in all groups tested (results not shown).

The results of serum biochemical analyses are summarized in Table 2. The marked increases in serum AST and ALT levels are attributed to severe damage in hepatic tissue membranes, because they are located in the cytoplasm and are released from cells after autolytic breakdown or cellular necrosis (Khan et al. 2012). The rats treated with 1,3-DCP showed a significant increase in the catalytic activities of serum AST and ALT, which indicated the induction of liver damage in the animals. However, the treatment of rats with $2 \%$ and $5 \%$ E. japonicum extract resulted in a significant decrease in the activities of these enzymes. Moreover, treatment with $C$. coreana Uyeki extract caused a more drastic reduction in enzyme activities, in a dose-dependent manner, and the AST and ALT levels almost reached the normal range following treatment with $5 \%$ C. coreana Uyeki extract. These results clearly suggested that $E$. japonicum and $C$. coreana Uyeki extracts may protect the liver against 1,3-DCP-induced damage in rats. However, the dose-dependency of extract was not observed in the $E$. japonicum-treated group. Therefore, further studies should be performed to elucidate the relationship between the attenuation of liver damage and the extract concentration used for treatment. Moreover, the molecular mechanism of the protective effect of extract remains unclear.

SOD and CAT are antioxidant enzymes known to scavenge free radicals in cells, and their catalytic activities indicate the oxidative status such as lipid peroxidation in organs with extensive cellular damage (Jurczuk et al. 2004). SOD and CAT assay with the liver homogenates was performed for all groups tested, and the results are summarized in Table 3. The activities of SOD and CAT were significantly diminished by treatment

Table 1 Body weight changes in male rats

\begin{tabular}{|c|c|c|c|c|c|c|}
\hline \multirow[t]{2}{*}{ Parameters } & \multicolumn{6}{|l|}{ Group } \\
\hline & Control & 1,3-DCP & $\begin{array}{l}\text { 2\% Erythronium } \\
\text { japonicum }\end{array}$ & $\begin{array}{l}\text { 5\% Erythronium } \\
\text { japonicum }\end{array}$ & $\begin{array}{l}2 \% \text { Corylopsis } \\
\text { coreana Uyeki }\end{array}$ & $\begin{array}{l}5 \% \text { Corylopsis } \\
\text { coreana Uyeki }\end{array}$ \\
\hline Before 1,3-DCP treatment & $296.3 \pm 12.45$ & $310.0 \pm 14.18$ & $302.3 \pm 26.79$ & $311.1 \pm 7.71$ & $313.9 \pm 13.90$ & $311.7 \pm 17.19$ \\
\hline After 1,3-DCP treatment & $303.5 \pm 16.41$ & $297.5 \pm 12.01$ & $296.2 \pm 29.55$ & $304.5 \pm 13.35$ & $308.5 \pm 10.25$ & $308.9 \pm 18.01$ \\
\hline Weight gain & $8.6 \pm 2.48$ & $-12.6 \pm 4.87^{* * *}$ & $-6.1 \pm 7.64^{* * * *}$ & $-6.6 \pm 8.89^{* * * *}$ & $-5.3 \pm 5.52^{* * * *}$, & $-2.8 \pm 5.83^{*, * *+\dagger}$ \\
\hline
\end{tabular}

1,3-DCP, 1,3-dichloro-2-propanol

Values are presented as means \pm SD $(g)$ of seven rats

Control represents a group without any treatments

"Significant difference at the $P<0.05$ level compared with the Control group

** Significant difference at the $P<0.01$ level compared with the Control group

'Significant difference at the $P<0.05$ level compared with the 1,3-DCP group

${ }^{+t}$ Significant difference at the $P<0.01$ level compared with the 1,3-DCP group 
Table 2 Effects of test materials on serum aspartate aminotransferase (AST) and alanine aminotransferase (ALT) activities in rats

\begin{tabular}{|c|c|c|c|c|c|c|}
\hline \multirow[t]{2}{*}{ Parameters } & \multicolumn{6}{|l|}{ Group } \\
\hline & Control & 1,3-DCP & $\begin{array}{l}\text { 2\% Erythronium } \\
\text { japonicum }\end{array}$ & $\begin{array}{l}\text { 5\% Erythronium } \\
\text { japonicum }\end{array}$ & $\begin{array}{l}2 \% \text { Corylopsis } \\
\text { coreana Uyeki }\end{array}$ & $\begin{array}{l}\text { 5\% Corylopsis } \\
\text { coreana Uyeki }\end{array}$ \\
\hline AST & $165.6 \pm 27.87$ & $16,326.7 \pm 2815.80^{* * * *}$ & $1816.0 \pm 2793.30^{\dagger \dagger}$ & $2524.0 \pm 2308.00^{\dagger \dagger}$ & $828.0 \pm 520.88^{+\dagger}$ & $360.0 \pm 247.79^{t \dagger}$ \\
\hline ALT & $65.3 \pm 34.89$ & $11,853.3 \pm 7052.20^{* * * *}$ & $1516.0 \pm 1805.60^{\dagger \dagger}$ & $1720.0 \pm 2188.01^{\dagger \dagger}$ & $972.0 \pm 695.93^{\dagger+}$ & $404.0 \pm 228.65^{+\dagger}$ \\
\hline
\end{tabular}

1,3-DCP, 1,3-dichloro-2-propanol

Values are presented as means \pm SD of seven rats

* Significant difference at the $P<0.05$ level compared with the Control group

${ }^{* *}$ Significant difference at the $P<0.01$ level compared with the Control group

'Significant difference at the $P<0.05$ level compared with the 1,3-DCP group

${ }^{++}$Significant difference at the $P<0.01$ level compared with the 1,3-DCP group

with 1,3-DCP. Based on this result and the increased values of AST and ALT shown in Table 2, it could be anticipated that 1,3-DCP induces liver toxicity by cellular necrosis, which may be associated with the increased production of reactive oxygen species due to decreased SOD and CAT activities in the liver (Haratake et al. 1993). In contrast, the activity of SOD and CAT were significantly restored by treatment with $5 \%$ E. japonicum or $5 \%$ C. coreana Uyeki extracts. However, the recovery effects were not apparent, or were marginal, in groups treated with $2 \%$ extracts. Nevertheless, these results indicated that the extracts of E. japonicum and C. coreana Uyeki play an important role in the recovery and/or protective effect against a decrease in anti-oxidant enzyme activities in the rat liver. The results also suggested that the reduction in AST and ALT activities in the serum following treatment with the extracts may be related with the restored enzymatic levels of SOD and CAT. However, the molecular mechanisms underlying the extract-mediated changes in enzyme activities of SOD and CAT, as well as AST and ALT, could not be elucidated through the current experiments.

To obtain further insight into 1,3-DCP-induced liver damage and the possible protective effect of E. japonicum and C. coreana Uyeki extracts on hepatic injury, we investigated the histopathological changes in the liver sections. It has been known that 1,3-DCP induces histopathological changes in the rat liver, including zonal necrosis of the centrilobular space, destruction of the sinusoidal structure, and increase in eosinophilic cellular debris and inflammatory cell infiltration in the necrotic areas (Choi et al. 2009; Stott et al. 1997). In the present study, the necrosis of hepatocytes and infiltration of inflammatory cells were observed around the central vein region of the rats in 1,3-DCP-treated group $(80 \mathrm{mg} / \mathrm{kg}$; Fig. 1b, f) compared with the normal liver tissue of control group (Fig. 1a, e). These are the typical histopathological features of liver injury caused by $1,3-\mathrm{DCP}$. However, the degree of hepatocyte necrosis and inflammation was alleviated around the central vein region of experimental groups treated with $5 \%$ E. japonicum (Fig. 1c, g) and 5\% C. coreana Uyeki extracts (Fig. 1d, h). Based on these results, we concluded that 1,3-DCP-induced hepatic lesions were reduced by treatment with both extracts. The appearance of the hepatocytes in the groups treated with the extracts were similar to that of the control group, which further support our conclusion.

It has been suggested that chlorogenic acid from $E$. japonicum is a candidate compound with protective function against oxidative stress-induced hepatotoxicity (Seo et al. 2016). Four marker compounds from C. coreana Uyeki have been identified: bergenin $(17.5 \%, \mathrm{w} / \mathrm{w})$; isosalipurposide $(8.6 \%, \mathrm{w} / \mathrm{w})$; quercitrin $(1.6 \%, \mathrm{w} / \mathrm{w})$; and quercetin $(0.05 \%, \mathrm{w} / \mathrm{w})$. Bergenin has a protective effect against d-galactosamine-induced hepatotoxicity in rats (Lim et al. 2001). Isosalipurposide, a chalcone

Table 3 Superoxide dismutase (SOD) and catalase (CAT) activities in the rat liver

\begin{tabular}{|c|c|c|c|c|c|c|}
\hline \multirow[t]{2}{*}{ Parameter } & \multicolumn{6}{|l|}{ Group } \\
\hline & Control & 1,3-DCP & $\begin{array}{l}2 \% \text { Erythronium } \\
\text { japonicum }\end{array}$ & 5\% Erythronium japonicum & $\begin{array}{l}2 \% \text { Corylopsis } \\
\text { coreana Uyeki }\end{array}$ & $\begin{array}{l}\text { 5\% Corylopsis } \\
\text { coreana Uyeki }\end{array}$ \\
\hline $\begin{array}{l}\text { SOD } \\
\text { (units/mg protein) }\end{array}$ & $174.6 \pm 33.88$ & $83.3 \pm 14.01^{* * * *}$ & $93.1 \pm 16.17^{* * * *}$ & $104.4 \pm 16.64^{* * * *}$ & $77.1 \pm 18.64^{* . * *}$ & $108.4 \pm 28.77^{*, * *}$ \\
\hline $\begin{array}{l}\text { CAT } \\
\text { (units/mg protein) }\end{array}$ & $11.49 \pm 1.415$ & $2.40 \pm 0.626^{* * *}$ & $2.92 \pm 0.638^{* * * *}$ & $4.59 \pm 0.712^{*, * *,+t}$ & $2.77 \pm 0.339^{* * * *}$ & $5.65 \pm 0.775^{* * * *,+十}$ \\
\hline
\end{tabular}

1,3-DCP, 1,3-dichloro-2-propanol

Values are presented as means \pm SD of seven rats

"Significant difference at the $P<0.05$ level compared with the Control group

"Significant difference at the $P<0.01$ level compared with the Control group

${ }^{+}$Significant difference at the $P<0.05$ level compared with the 1,3-DCP group

${ }^{+t}$ Significant difference at the $P<0.01$ level compared with the 1,3-DCP grou 


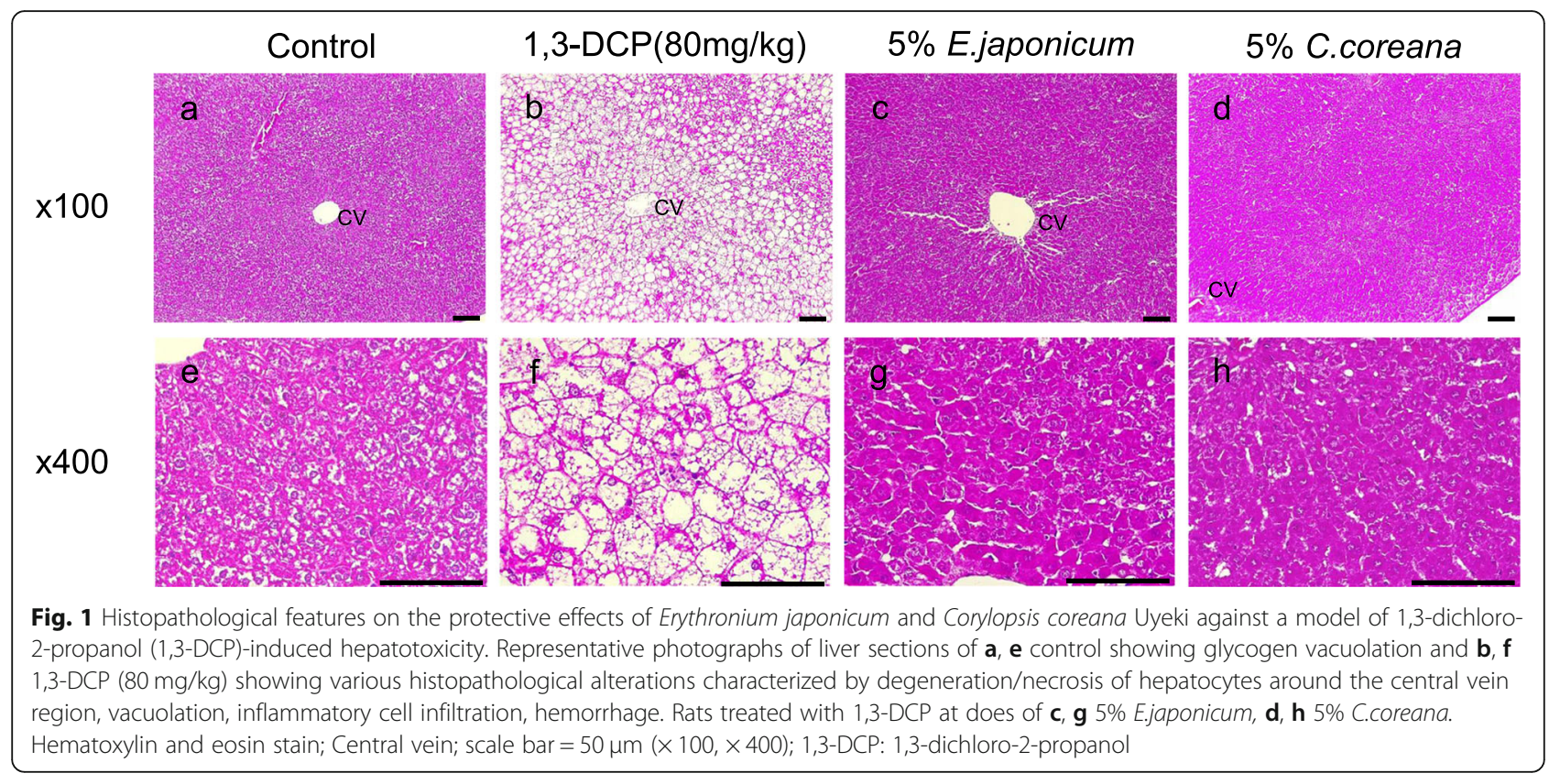

compound, exerts a cytoprotective effect against oxidative injury through Nrf2 activation (Han et al. 2015). Quercitrin and quercetin protect the liver from acetaminophen-induced injury (Shanmugam et al. 2016; Xie et al. 2016). Quercitrin is a glycoside formed from quercetin, which is known to deplete the heme pool and induce carbon monoxide release, thereby limiting the expression and activity of CYP2E1, a well-known enzyme that induce oxidative stress (Tang et al. 2013; Leung and Nieto 2013). These results, therefore, suggest that certain component(s) in these plant extracts may alleviate the 1,3-DCP-mediated hepatotoxicity of rats.

\section{Conclusion}

E. japonicum and C. coreana Uyeki extracts alleviated the 1,3-DCP-induced decrease in body weight and the enzyme activities of AST and ALT in the rat serum. In addition, the extracts restored the decreased activities of SOD and CAT in the rat liver homogenates. These results indicated the protective effect of the extracts on 1 , 3-DCP-mediated liver injury and this conclusion was further supported by histopathological results. Collectively, the present study provide a possibility that the extracts of E. japonicum and C. coreana Uyeki may be applied to remedy of 1,3-DCP-induced hepatotoxicity in animals.

\footnotetext{
Abbreviations

E. japonicum: Erythronium japonicum; C. coreana Uyeki: Corylopsis coreana Uyeki; 1,3-DCP: 1,3-dichloro-2-propanol; AST: Aspartate aminotransferase; ALT: Alanine aminotransferase; SOD: Superoxide dismutase; CAT: Catalase
}

Acknowledgements

Not applicable.

\section{Authors' contributions}

Seunghyun Kim (First Author): performed all experiments throughout the studies. Hee-Ock Boo (Second Author): designed the overall experiments to achieve the goal of the current works. Taeho Ahn (Co-Corresponding Author): interpreted the experimental results obtained by Dr. Kim and also has prepared the draft manuscript. Chun-Sik Bae (Corresponding Author): directed all the experimental processes and also has completed writing the manuscript. The author(s) read and approved the final manuscript.

\section{Funding}

Not applicable.

\section{Availability of data and materials}

Materials described in the manuscript, including all relevant raw data, will be freely available to any scientist wishing to use them for non-commercial purpose.

\section{Ethics approval and consent to participate}

Not applicable.

\section{Consent for publication}

Not applicable.

\section{Competing interests}

Not applicable.

\section{Author details}

${ }^{1}$ College of Veterinary Medicine, Chonnam National University, Gwangju 61186, South Korea. ${ }^{2}$ Wellphyto Co. Ltd, Gwangju 61950, South Korea.

Received: 12 October 2020 Accepted: 24 November 2020

Published online: 02 December 2020

\section{References}

H. Aebi, Catalase in vitro. Methods Enzymol. 105, 121-126 (1984)

C.S. Bae, C.H. Yun, T. Ahn, Extracts from Erythronium japonicum and Corylopsis coreana Uyeki reduce 1,3-dichloro-2-propanol-mediated oxidative stress in human hepatic cells. Food Sci. Biotechnol. 28, 175-180 (2018)

C. Beauchamp, I. Fridovich, Superoxide dismutase: Improved assays and an assay applicable to acrylamide gels. Anal. Biochem. 44, 276-287 (1971)

H.O. Boo, J.H. Shin, E.S. Choung, M. Bang, K.M. Choi, W.S. Song, Carbohydrate, Lipid inhibitory activity and antioxidant activity of extracts from several economic resource Plants in Vitro. Korean J. Plant Res. 26, 374-382 (2013) 
K. Choi, J. Kim, G.W. Kim, C. Choi, Oxidative stress-induced necrotic cell death via mitochondria-dependent burst of reactive oxygen species. Curr. Neurovasc. Res. 6, 213-222 (2009)

A. Deters, A. Dauer, E. Schnetz, M. Fartasch, A. Hensel, High molecular compounds (polysaccharides and proanthocyanidins) from Hamamelis virginiana bark: Influence on human skin keratinocyte proliferation and differentiation and influence on irritated skin. Phytochemistry 58, 949-958 (2001)

A.H. Hammond, J.R. Fry, Effect of cyanamide on toxicity and glutathione depletion in rat hepatocyte cultures: Differences between two dichloropropanol isomers. Chem. Biol. Interact. 122, 107-115 (1999)

J.Y. Han, S.S. Cho, J.H. Yang, K.M. Kim, C.H. Jang, D.E. Park, J.S. Bang, Y.S. Jung, S.H. $\mathrm{Ki}$, The chalcone compound isosalipurposide (ISPP) exerts a cytoprotective effect against oxidative injury via Nrf2 activation. Toxicol. Appl. Pharmacol. 287, 77-85 (2015)

J. Haratake, A. Furuta, T. Iwasa, C. Wakasugi, K. Imazu, Submassive hepatic necrosis induced by dichloropropanol. Liver 13, 123-129 (1993)

B.G. Heo, Y.S. Park, S.U. Chon, S.Y. Lee, J.Y. Cho, S. Gorinstein, Antioxidant activity and cytotoxicity of methanol extracts from aerial parts of Korean salad plants. BioFactors 30, 79-89 (2007)

M. Jurczuk, M.M. Brzóska, J. Moniuszko-Jakoniuk, M. Gałażyn-Sidorczuk, E. Kulikowska-Karpińska, Antioxidant enzymes activity and lipid peroxidation in liver and kidney of rats exposed to cadmium and ethanol. Food Chem. Toxicol. 42, 429-438 (2004)

T. Katoh, J. Haratake, S. Nakano, M. Kikuchi, M. Yoshikawa, K. Arashidani, Dosedependent effects of dichloropropanol on liver histology and lipid peroxidation in rats. Ind. Health 36, 318-323 (1998)

R.A. Khan, M.R. Khan, S. Sahreen, N.A. Shah, Hepatoprotective activity of Sonchus asper against carbon tetrachloride-induced injuries in male rats: $A$ randomized controlled trial. BMC Complement. Altern. Med. 12, 90 (2012)

J. Kim, D. Shin, S. Kim, J. Kim, S. Park, W. Son, H. Lee, J. Suh, C. Kim, C. Ha, Subacute toxicity evaluation of a new camptothecin anticancer agent CKD602 administered by intravenous injection to rats. Regul. Toxicol. Pharmacol. 40, 356-369 (2004)

M.H. Kim, S.Y. Ha, M.H. Oh, H.H. Kim, S.R. Kim, M.W. Lee, Anti-oxidative and antiproliferative activity on human prostate cancer cells lines of the phenolic compounds from Corylopsis coreana Uyeki. Molecules 18, 4876-4886 (2013)

H.C. Korting, M. Schäfer-Korting, H. Hart, P. Laux, M. Schmid, Anti-inflammatory activity of hamamelis distillate applied topically to the skin. Eur. J. Clin. Pharmacol. 44, 315-318 (1993)

J. Lee, I. Shin, T. Ahn, K. Kim, C. Moon, S. Kim, D. Shin, S. Park, Y. Kim, J. Kim, Developmental toxic potential of 1,3-dichloro-2-propanol in Sprague-Dawley rats. Regul. Toxicol. Pharmacol. 53, 63-69 (2009)

T.M. Leung, N. Nieto, CYP2E1 and oxidant stress in alcoholic and non-alcoholic fatty liver disease. J. Hepatol. 58, 395-398 (2013)

H.K. Lim, H.S. Kim, H.S. Choi, J. Choi, S.H. Kim, M.J. Chang, Effects of bergenin, the major constituent of Mallotus japonicus against d-galactosamine-induced hepatotoxicity in rats. Pharmacology 63, 71-75 (2001)

D. Lizárraga, S. Touriño, F.J. Reyes-Zurita, T.M. de Kok, J.H. van Delft, L.M. Maas, J.J. Briede, J.J. Centelles, J.L. Torres, M. Cascante, Witch hazel (Hamamelis virginiana) fractions and the importance of gallate moieties electron transfer capacities in their antitumoral properties. J. Agric. Food Chem. 56, 11675-11682 (2008)

P. Nyman, G. Diachenko, G. Perfetti, Survey of chloropropanols in soy sauces and related products. Food Addit. Contam. 20, 909-915 (2003)

J.H. Seo, M. Bang, G. Kim, S.S. Cho, D.H. Park, Erythronium japonicum attenuates histopathological lung abnormalities in a mouse model of ovalbumininduced asthma. Int. J. Mol. Med. 37, 1221-1228 (2016)

S. Shanmugam, P. Thangaraj, B. dos Santos Lima, R. Chandran, A.A. de Souza Araújo, N. Narain, M.R. Serafini, L.J.Q. Júnior, Effects of luteolin and quercetin

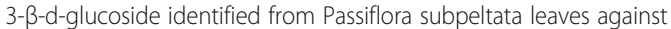
acetaminophen induced hepatotoxicity in rats. Biomed. Pharmacother. 83, 1278-1285 (2016)

I. Stott, A. Murthy, A. Robinson, N.W. Thomas, J.R. Fry, Low-dose diethyldithiocarbamate attenuates the hepatotoxicity of 1,3-dichloro-2propanol and selectively inhibits CYP2E1 activity in the rat. Human Exp. Toxicol. 16, 262-266 (1997)

Y. Tang, H. Tian, Y. Shi, C. Gao, M. Xing, W. Yang, W. Bao, D. Wang, L. Liu, P. Yao, Quercetin suppressed CYP2E1-dependent ethanol hepatotoxicity via depleting heme pool and releasing CO. Phytomedicine 20,699-704 (2013)

W. Xie, M. Wang, C. Chen, X. Zhang, M.F. Melzig, Hepatoprotective effect of isoquercitrin against acetaminophen-induced liver injury. Life Sci. 152, 180 189 (2016)

\section{Publisher's Note}

Springer Nature remains neutral with regard to jurisdictional claims in published maps and institutional affiliations.

\section{Submit your manuscript to a SpringerOpen ${ }^{\circ}$ journal and benefit from:}

- Convenient online submission

- Rigorous peer review

- Open access: articles freely available online

- High visibility within the field

- Retaining the copyright to your article

Submit your next manuscript at $\boldsymbol{\nabla}$ springeropen.com 